\title{
Scientific Bulletin of Naval Academy
}

SBNA PAPER • OPEN ACCESS

\section{Maintenance onboard ships using computer maintenance management system}

To cite this article: Dragoș Simion, Alexandra Purcărea, Alexandru Cotorcea and Florin Nicolae, Scientific Bulletin of Naval Academy, Vol. XXIII 2020, pg.134-141. 


\title{
Maintenance onboard ships using computer maintenance management system
}

\author{
Dragoș Simion ${ }^{1}$, Alexandra Purcărea ${ }^{2}$, Alexandru Cotorcea ${ }^{3}$, Florin \\ Nicolae $^{4}$ \\ ${ }^{1}$ Eng. PhD attendee, "Mircea cel Bătrân" Naval Academy, Constanta, Department of \\ Naval and Port Engineering and Management \\ ${ }^{2}$ Professor, PhD Eng., Politehnica University, Bucharest, School of Postgraduate \\ Academic Studies in Management \\ ${ }^{3}$ Lecturer, PhD Eng., "Mircea cel Bătrân" Naval Academy, Constanta, Department of \\ Naval and Port Engineering and Management \\ ${ }^{4}$ Professor, PhD Eng., "Mircea cel Bătrân" Naval Academy, Constanta, Department \\ of Naval and Port Engineering and Management \\ E-mail address : alexandru.cotorcea@anmb.ro
}

Abstract. The importance and the role of the maintenance process are based on keeping the equipment and systems in an operative state of readiness. On the other hand, the knowledge of legislative framework, as well as the learning the practical skills lead to the successful application of the maintenance programs within the organizations.

Regarding these aspects, the present paper addresses the topic of maintenance onboard ships. The general legislative framework for management and execution of the maintenance process specific to the maritime domain is presented, as well as the methods implemented onboard ships. It is described how to perform the maintenance of the equipment for a special ship using a computer maintenace management softwere. The study takes into account the constructive features, the equipment and the missions of the ship.

Keywords: onboard maintenance, risk in maintenance, computer maintenace management system

\section{Introduction}

Safety is a critical issue in all marine industry sectors, this is clearly illustrated in the latest statistics and accident reports in the field. In a study regarding maritime accidents between 2002 and 2016 the inappropriate/ineffective maintenance was identified as an overall cause of all type of accident for about $12.1 \%$ of cases. Also, a fairly large percentage, $11.5 \%$ of cases, produced as a result of a technique of equipment failures. [1].

Ships are complex products with a long lifespan and high costs for building, operation, maintenance and repair. It is well known that the decisions during the design stage have a major impact on the life cycle of the ship (costs, performance, etc.). The lifecycle management represent a challenge for naval architects, shipbuilding engineers and operating personnel, taking into consideration the capital investment, harsh environment conditions and long service life (25-30 years) [2]

Different shipbuilding features depend on the type, mission, capacity of carrying goods, environment conditions of transit area, ports facilities and the initial investments for design and construction. In order to have an overview of the types of ships operating in the maritime field, it is necessary to classify them, in terms of the missions they can perform, as follows: [3]

- transport (cargo, container, passenger ships) 
- non transport (fishing vessels, service craft - tugs and supply vessel, warships - naval and coast guard vessel)

Given the specific nature of maritime transport, the costs of causing damage are difficult to estimate, as they are unforeseen situations with unpredictable consequences. Experts estimate that in the 1990s, about $36 \%-56 \%$ of ship operating costs were used to prevent and repair damage, including insurance. [4]

The article is structured in three main sections and the topic brought into attention is how to implement maintenance management on a special ship by using a software solution.

First section summaries notions about maintenance theory by defining the specific terms, classification, role and importance of different maintenance types. The objective is to identify, analyzed and ordered the concepts regarding terminologies in this field. These notions must be well understood both by the maintenance personnel, but also by the staff responsible for planning and establishing the maintenance strategy within the organization.

Second section addresses the issue of ship maintenance starting from a short presentation of the legislative framework governing maritime maintenance related activities.

Last section presents the process of implementing a maintenance management program for a military ship in order to avoid breakdowns, reducing downtime, collecting data and information, improving health and safety and increasing efficiency.

\section{Maintenance approaches}

Maintenance theory is in a continuous development, starting with the 1960s. Thus, in the literature can be found numerous definitions of the terms maintenance, maintainability, maintenance strategy or maintenance policy. [5]

Traditionally, maintenance was defined as a component of a production process. The main purpose of maintenance is to optimize the availability of equipment at a lowest cost. When the concept of sustainable development was brought into discussion maintenance was integrated into the life cycle of the product, as well as economic, environmental and social factor. [6]

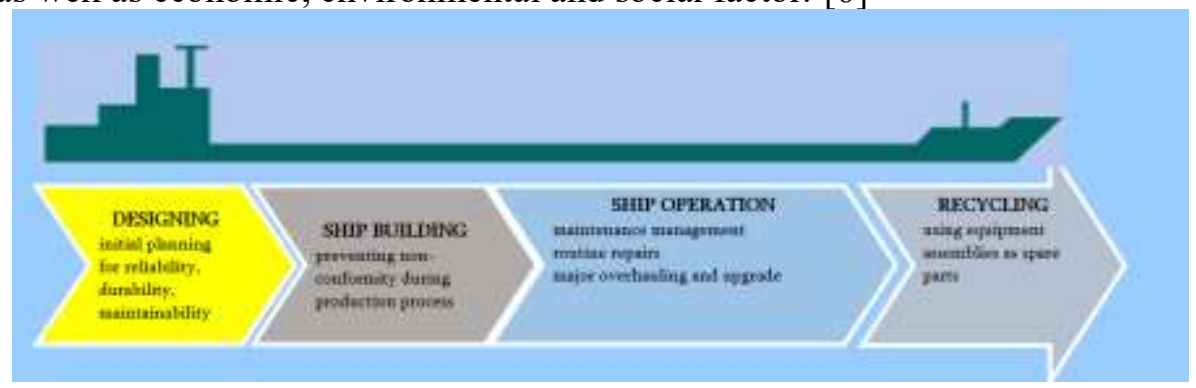

Figure 1. Maintenance in ships life cycle [6,7]

\subsection{Maintenance definition.}

The term "maintenance" has been defined in various forms, ranging from the complexity of the works, the industry in which the equipment is operated to the professional experience and field of expertise of the authors. The concept was first developed and formalized by production industry in the late 1970s.

The European standard EN 13306: 2017, specifies generic terms and definitions for the technical, administrative and managerial areas of maintenance: [8]

- maintenance - "combination of all technical, administrative and managerial actions during the life cycle of an item intended to retain it in, or restore it to, a state in which it can perform the required function"

- maintenance management - "all activities of the management that determine the maintenance objectives, strategies and responsibilities, and implementation of them by such means as maintenance planning, maintenance control, and the improvement of maintenance activities and economic" 
- maintainability - "ability of an item under given conditions of use, to be retained in, or restored to, a state in which it can perform a required function, when maintenance is performed under given conditions and using stated procedures and resources"

- failure - "termination of the ability of an item to perform a required function"

- down time - "time interval throughout which an item is in a down state".

\subsection{Maintenance types}

Over time, maintenance has been seen as the "necessary evil", then "a means of increasing profit" and now as an "integral part of the organization", the evolution taking place over four generations, starting from 1950. [9]

Traditionally, maintenance is classified into planned or unplanned. According to European standard EN 13306: 2017 maintenance can be preventive or corrective. The standard classifies preventive maintenance into two distinct types, planned maintenance, which has a time-based execution interval, and conditional maintenance with a different execution dynamic [7]. Other authors consider conditional maintenance as predictive maintenance. Short definition and differences of maintenance types are presented in figure 2 .

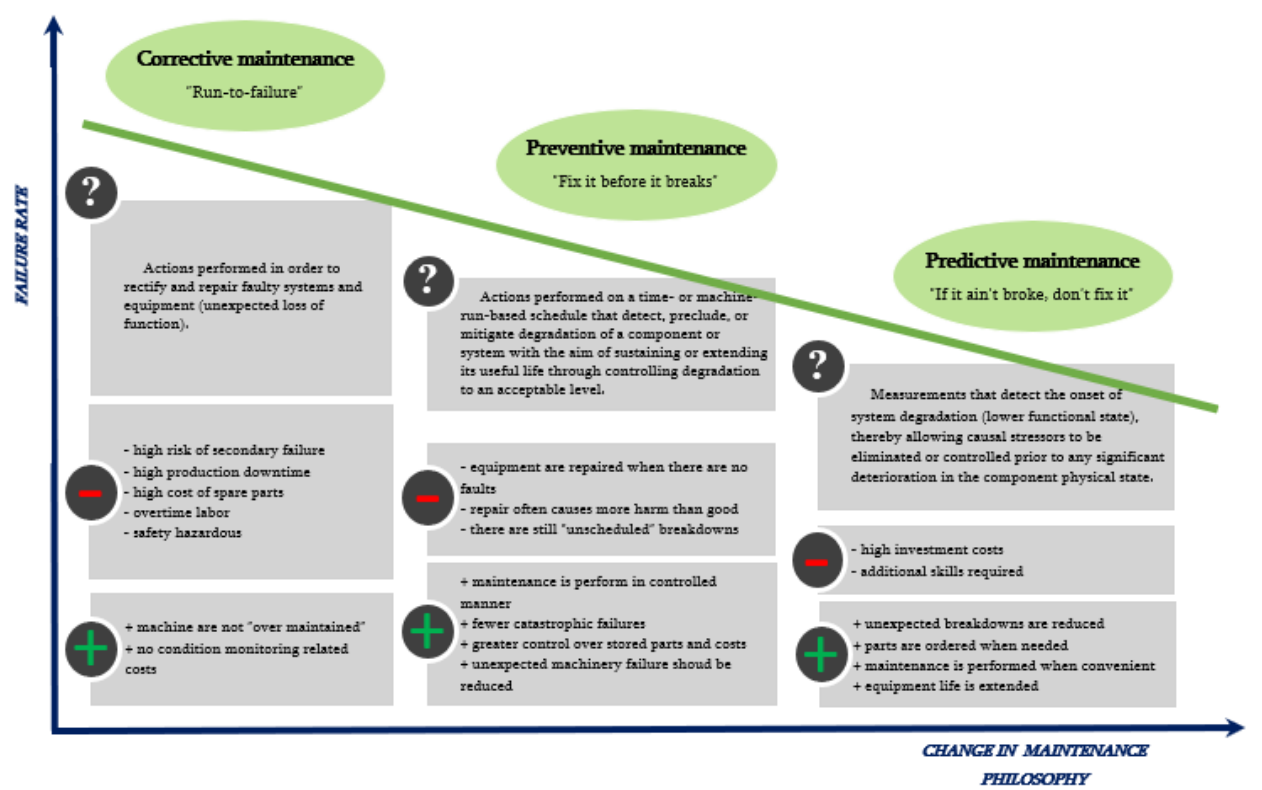

Figure 2. Definition and differences of maintenance types [10]

According to US standard maintenance is classified in "reactive, preventive, predictive and reliability-centered" [11]. Khazraei and Deuse proposed two main types of maintenance and the various tactics linked with them - reactive (corrective, prospective) and preventive (predetermined, proactive, predictive). [12]

There is still a great deal of confusion in maintenance management regarding the terminology used to define and classified maintenance types. Even if the terminology may vary it is necessary to understand the concept of terms presented above. For these reason Trojan proposal for sorting maintenance types take into account criteria like: associated risks, modes of intervention, action planning, costs and resources available in each type of maintenance. The study classifies maintenance into four major areas: reactive, proactive, predictive, and advanced (figure 3 ). 


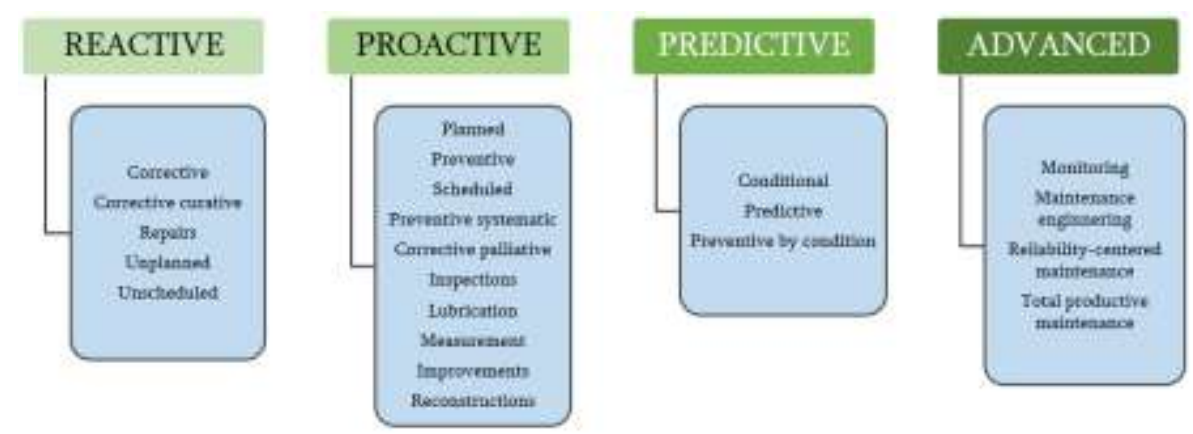

Figure 3. Type of maintenance [13]

In conclusion, an effective maintenance program will follow the principles and approaches of the different types of maintenance presented above.

\section{Ship maintenance}

\subsection{Legislative framework}

In order to ensure that ships to meet the minimum structural an operating standard required by the IMO, they are classified by special organizations, called classification societies. A classification society formulates the rules, validates the model (design), elaborates the safety standards that the ship and the equipment on board must comply.

In 1993, the IMO introduced the International. Safety Management Code (ISM), which lays the groundwork for a preventive maintenance system. Chapter 10 specifies the procedures, requirements and obligations that companies must implement in order to ensure compliance with international regulations.

The main purpose of performing equipment maintenance, from a technical point of view, was to prevent damage and thus reduce operating time, if they had occurred. In recent years, shipping has adapted to international standards and recommendations set by the International Maritime Organization (IMO) and other advisory bodies in the field.

Regarding the maintenance management system of the ship the following objectives must be considered: [14]

- be very well structured;

- to have a certain flexibility;

- to allow obtaining feedback;

- be designed by experts in the field;

- allow for periodic evaluation and changes accordingly;

- allow the storage of information on the history of maintenance works.

Military vessels are not required to comply with the rules and regulations of the IMO Convention, they must meet the requirements of national legislation. In this case, military ships were not classified in a similar way as merchant ships.

However, in the last two decades classification societies such as American Bureau of Shipping (ABS) and Lloyd's Register (LR) in collaboration with the defense authorities of the partner states have laid the foundations for a set of special rules on design and capabilities for military vessels. The first state that implement the classification system was France for the construction of "Mistral" class ships. In the future, the adoption of these sets of rules will have a major contribution for an increasing interoperability capacity of military equipment and for lowering the design and construction cost of new military ship projects. [15]

\subsection{The evolution of the maintenance concept in shipping}

Maintenance of the ship and onboard systems has evolved with the requirements introduced by IMO and the rules of classification societies. All maintenance procedures have so far tried to compensate for 
the differences between the theoretical solutions offered by the maintenance strategies and the practical implementation onboard ships. Difficulties were encountered due to the complexity of the onboard equipment and systems on several levels: data collection and large volume of maintenance information, implementation of correct maintenance procedures, monitoring of operating parameters and maintenance, etc.

At the beginning corrective maintenance has been the maintenance strategy adopted onboard ships. The recommendation of IACS (International Association of Classification Societies) states that in order to perform corrective maintenance, certain steps must be followed:

- fault recognition;

- establishing the causes of the failure;

- troubleshooting options;

- implementation of corrective measures.

Preventive maintenance is performed to prevent accidental equipment failure by performing planned repairs or replacement of worn parts according to an established procedure. Preventive maintenance was followed by predictive maintenance when it was possible to assess the state of the equipment and applied maintenance procedures in order to prevent breakdown. Other benefits that predictive maintenance brought were:

- optimization of intervals for the execution of maintenance works;

- extending the period of use of the parts (by evaluating the wear);

- only replacement of spare parts and reduction of cost with spare parts.

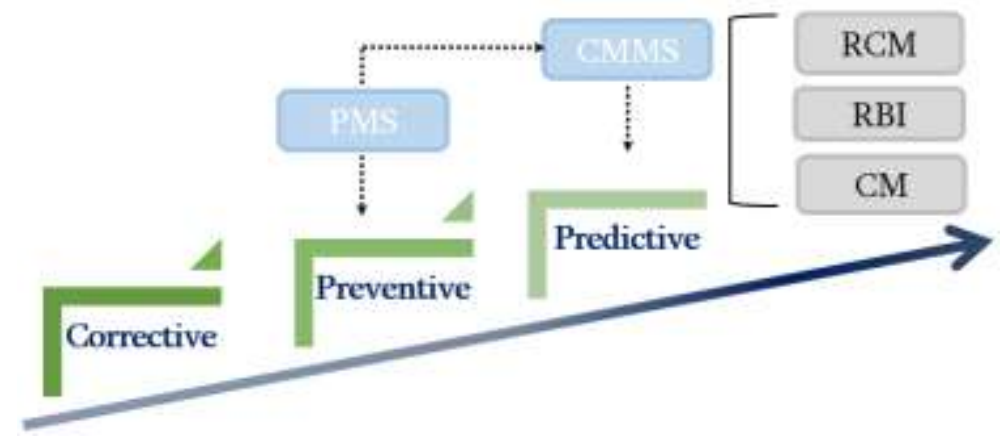

Figure 4. The evolution of the maintenance process in the shipbuilding industry [14]

In figure 4, predictive maintenance is divided into three different categories: reliability-centered maintenance $(\mathrm{RCM})$, risk-based inspection (RBI) and condition monitoring (CM). Preventive and predictive maintenance methods have evolved by implementing IT solution for managing the maintenance process.

\subsection{Computerized maintenance management system}

Shipowners must ensure and implement preventive operation and maintenance procedures for on-board equipment and systems in accordance with the ISM Code. Maintenance onboard ship can be performed by implementing maintenance management software, by using written procedures or by combining the two methods. [16]

A planned maintenance system (PMS) allows shipowners and operating personnel to plan, perform and document the maintenance procedures for system onboard at time intervals in accordance with the manufacturer guidelines and class requirements. The early PM programs were frequently implemented on manual, card-based systems. Things have changed with the introduction and advancement of computers and information technology. [17]

In 1984, the first planned maintenance software specifically designed for shipping industry, called the Asset Management Operating System (AMOS) and used the MS-DOS operating program, was implemented onboard merchant ships. The PMS has evolved permanently and finely became the computerized maintenance management system (CMMS), which is a software solution through which 
the maintenance program of the on-board technology is implemented. Today, the programs contain not only the maintenance management module but also other modules developed in order to manage information and increase the operational safety of the ship.

For military ships, the maintenance planning system was not a mandatory requirement to classify the ship, as is the case with merchant ships. CMMS solutions implemented onboard merchant ships are offered both by recognized IT companies (e.g., Spec Tec Company - AMOS, BASS - BASS net, AVECS Corporation - TITAN) but also by large shipping companies, which have created their own system for ships in the fleet. [18]

US Navy has conducted several studies since 1972 on the possibility of using automatic data processing systems onboard military ships. The researches led to the development by Navy Management System Support Office (NAVMASSO) of a software called Shipboard Non-tactical Automated Data Processing Program (SNAP II), with six main modules (supply, pay/disbursing, administration, maintenance, personnel and medical) and it was used onboard ships since 1981. [19]

One of the latest advances in the field is the Maintenance Figure of Merit (MFOM) system that allows the collection of maintenance data from numerous existing sources and compare them with models developed by maintenance experts to predict fleet readiness. [20]

\section{Improving maintenance management on a special ship using a CMMS program}

Furthered is presented the process of implementing a maintenance management program for a military ship and for this it was used the equipment data installed onboard training ship Mircea, a ship with 80 years of service. The logical scheme for implementing a CMMS program is presented in figure 5.

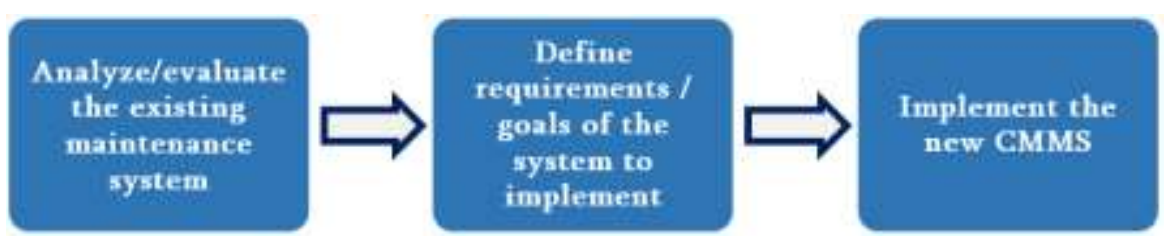

Figure 5. Logical sequence to implement a CMMS in an organization [21]

Over the years the ship went through several stages for improvement and overhauling the main systems and equipment, the last major repair being carried out between 1994 and 2002.

Maintenance data (e.g., work order, fault history, operating and maintenance procedures, operating hours) are largely stored in printed format using specific forms (e.g., operating books, registers / operating logs). IT systems are used only for keep track of running hours of equipment and for sending periodic request and report to logistic department.

The maintenance program that applies to the on-board equipment involves the application of corrective and preventive maintenance measures. Each equipment on board follows a preventive maintenance program (at intervals or duration of operation) to keep it operational and to prevent accidental falls. If breakdowns occur, the maintenance staff onboard apply maintenance corrective measures. Usually, every three years, the ship is drydocked for the execution of specific works: routine repairs for the ship's hull and freeboard, major repairs to the body, accommodations and decks (replacement of steel affected by corrosion), inspection for propeller, shaft and rudder.

In the last ten years, the ship has undergone a modernization program in which the following have been replaced: navigation and communications equipment, modernization of the power plant, main engine and propulsion system overhaul, improvements/retrofitting of the steering gear system.

Objectives for which it is desired to implement such a system on board military ships is to improve maintenance procedures in order to increase equipment availability, avoid machinery breakdowns, better execution of repairs in case of failure and reduce maintenance costs.

In order to achieve the objectives, it is necessary that the CMMS solution allows:

- creating a complete database of equipment, equipment and accessories on board; 
- recording the relevant data from the maintenance activity (e.g., technical data, measured parameters, maintenance history);

- creating a maintenance plan for all equipment;

- spare parts stock management;

- use the maintenance history to optimize maintenance plans;

- managing maintenance resources for better asset utilisation;

- employee positioning and workload allocation;

- use of standardized workorders;

- performance evaluation.

For the practical implementation of a CMMS program it is necessary to plan and execute some activities in order to prepare and use the software and all of it features, by following the framework presented in figure 6 .

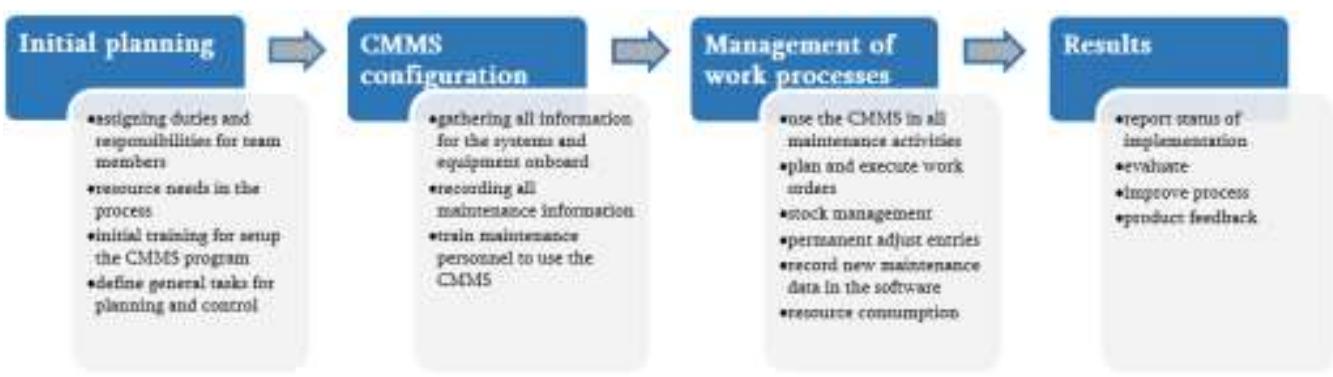

Figure 6. Framework to implement CMMS

All these steps must be undertaken by the maintenance staff and a clear conception about how this process can improve overall efficiency and a correct estimation of cost (e.g., for software, training, data gathering, ongoing cost of maintenance) will lead to a successful implementation of CMMS.

\section{Conclusions}

Sustainable working methods together with maintenance policies adapted for each domain are the preconditions for any maintenance management strategy.

Maintenance on board ships needs to be carried out in a planned manner, as the safe and efficient operation of a ship depends very much on the reliability of the equipment at the operational level. A planned maintenance system is a useful tool for managing the large volume of data for operations and maintenance history of on-board systems.

By analyzing the proposed framework, it is clear that implement a CMMS is a long-term commitment and that all personnel on board will be part of the process at some point. Starting with the initial planning, each step should be evaluated and if errors occurs staff management will take measures in order to overcome the risk of improper use of the CMMS in all maintenance related activities.

Further research may involve identifying software solutions offered by the market. After analyzing options, features and long-term benefits of the programs the proper solution will be chose for implement onboard a military vessel.

\section{References}

[1] Acejo, I., Sampson, H., Turgo, N., Ellis, N., Tang, L. The causes of maritime accidents in the period 2002-2016, Seafarers International Research Centre, Cardiff University, 2018

[2] Favi, C., Germani, M., Campi, F., Mandolini, M., Manieri, S., Marconi, M., Vita, A., Life cycle cmdel and metrics in shipbuilding: how to use them in the preliminary design phases, In Procedia CIRP (Vol. 69, pp. 523-528). Elsevier B.V., 2018, https://doi.org/10.1016/j.procir.2017.11.071

[3] Molland, A.F., The maritime engineering reference book: a guide to ship design, construction 
and operation, ISBN 9780080560090 , Elsevier Science, 2008

[4] Thoben, K. D., Homburg, N., Maritime life cycle management during ship operation, International Conference on Product Lifecycle Management, 2009

[5] Nowakowski, T., Tubis, A., Werbińska-Wojciechowska, S., Evolution of technical systems maintenance approaches - review and a case study, Intelligent Systems in Production Engineering and Maintenance, 2019

[6] Malgorzata, J-K., The role of ergonomics in implementation of the social aspect of sustainability, illustrated with the example of maintenance, Occupational Safety and Hygiene. CRC Press, Taylor \& Francis: London, ISBN 9781138000476, pp. 47-52, 2013

[7] Ang J. H., Goh C., Flores Saldivar A.A., Li Y., Energy-Efficient Through-Life Smart Design, Manufacturing and Operation of Ships in an Industry 4.0 Environment, 2017

[8] Maintenance european Standard EN-13306-2017

[9] Arunraj, N., S., Maiti, J., Risk-based maintenance - techniques and applications, Journal of Hazardous Materials, 142, 653-661, 2007

[10] Bengtsson M., Olsson E., Funk P. and Jackson M., Technical design of condition based maintenance system - a case study using sound analysis and cased-based reasoning, Proceedings of the 8th Conference of Maintenance and Reliability, Knoxville, 2004

[11] US DOE, Operation and maintennce best practice guide, release 3.0, US Department of Energy, Washington, 2010

[12] Khazraei K., Deuse J., A strategic standpoint on maintenance taxonomy, Journal of Facilities Management, Vol. 9, No. 2, pp. 96-113, 2011

[13] Trojan, F., Marçal R. F. M., Proposal of maintenance types. classification to clarify maintenance concepts in production and operations management, Journal of Business Economics, 2017

[14] Lazakis, I., Turan, O., Aksu, S., Increasing ship operational reliability through the implementation of a holistic maintenance management strategy, Ships and Offshore Structures Vol. 5, No. 4, 2010, 337-357, 2010

[15] Narula K., Agarvala N., Classification Rules for Naval Warships: Heralding a Change, 2015

[16] The International Safety Management Code (ISM). The International Maritime Organisation (IMO), 2002

[17] Chang, V.T., Dung V.A., Thien D.M., Bich V.N., Implementation of the Computerized Maintenance Management Systems (CMMS) for the Maritime Industry, Proceedings of the International MultiConference of Engineerrs and Computer Scientist Vol. II, Hog Kong, 2011

[18] Gašpar, G., Poljak, I., Orović, J., Computerized Planned Maintenance System software models, Scientific Journal of Maritime Research 32 (2018) 141-145 (C) Faculty of Maritime Studies Rijeka, 2018

[19] McMican, W. J., Richards, J.J., Shipboard non-tactical computer systems of the U.S. Navy, Naval Postgraduate School, Monterey, California, 1985

[20] Martin B., Yardley R.J., Phillip Pardue, Brynn Tannehill, Emma Westerman, Jessica Duke, An Approach to Life-Cycle Management of Shipboard Equipment, rand Corporatios, Snata Monica, California, 2018

[21] Corniciuc, C., Veríssimo, A., Case study: implementing a CMMS for maintenance management in a university campus, 2017 